\title{
Contrastive Knowledge Surveyed
}

\author{
JONATHAN SCHAFFER \\ JOSHUA KNOBE \\ Yale University
}

Australian National University

Suppose that Ann says, "Keith knows that the bank will be open tomorrow." Her audience may well agree. Her knowledge ascription may seem true. But now suppose that Ben - in a different context-also says "Keith knows that the bank will be open tomorrow." His audience may well disagree. His knowledge ascription may seem false. Indeed, a number of philosophers have claimed that people's intuitions about knowledge ascriptions are context sensitive, in the sense that the very same knowledge ascription can seem true in one conversational context but false in another.

This purported fact about people's intuitions serves as one of the main pieces of evidence for epistemic contextualism, which is (roughly speaking) the view that the truth conditions of a knowledge attribution can differ from one conversational context to another. Opponents of contextualism have replied by trying to explain these purported intuitions in other ways. For instance, they have proposed that these purported intuitions may be explained via shifts in what is at stake for the subject, pragmatic shifts in what is assertible, or performance shifts in our liability to error.

Yet a recent series of empirical studies threatens to undermine this whole debate. These studies presented ordinary people with precisely the sorts of cases that have been discussed in the contextualism literature and gave them an opportunity to say whether they agreed or disagreed with the relevant knowledge attributions. Strikingly, the results suggest that people simply do not have the intuitions they were purported to have. Looking at this recent evidence, it is easy to come away with the feeling that the whole contextualism debate was founded on a myth. The various sides offered 
conflicting explanations for a certain pattern of intuitions, but the empirical evidence suggests that this pattern of intuitions does not exist.

Our aim is to defend a form of contextualism in the face of this new threat. We acknowledge that some of the specific claims made by earlier contextualists might be undermined by recent experimental results, but we suggest that a different form of contextualism-based on the idea that conversational context provides the relevant contrast - can answer this empirical challenge. We then report a new series of experimental studies that provide empirical support for a contrastive view of knowledge.

Overview: In $\S \S 1-2$ we will display the assumptions about our intuitions found in the contextualism debate, and review the recent empirical studies challenging these assumptions. In $\S \S 3-5$ we will introduce a contrastive model, and provide new empirical results supporting this model. We will conclude in $\$ \S 6-7$ by comparing our contrastive model to invariantist models and to other contextualist models.

\section{Contextualism and Our Intuitions}

Do our intuitions support contextualism? The participants in the contextualism debate have generally supposed that ordinary speakers shift from attributing knowledge in 'low stakes' cases, to attributing ignorance in 'high stakes' cases. DeRose's (1992: 913) bank cases, Cohen's (1999: 58) airport cases, and Fantl and McGrath's (2002: 67-8) train cases are among the cases said to illustrate such shiftiness. Here are DeRose's bank cases:

Low My wife and I are driving home on a Friday afternoon. We plan to stop at the bank on the way home to deposit our paychecks. But as we drive past the bank, we notice that the lines inside are very long, as they often are on Friday afternoons. Although we generally like to deposit our paychecks as soon as possible, it is not especially important in this case that they be deposited right away, so I suggest that we drive straight home and deposit our paychecks on Saturday morning. My wife says, "Maybe the bank won't be open tomorrow. Lots of banks are closed on Saturdays." I reply, "No, I know it'll be open. I was just there two weeks ago on Saturday. It's open until noon."

High My wife and I drive past the bank on a Friday afternoon, as in [Low], and notice the long lines. I again suggest that we deposit our paychecks on Saturday morning, explaining that I was at the bank on Saturday morning only two weeks ago and discovered that it was open until noon. But in this case, we have just written a very large and very important check. If our paychecks are not deposited into our checking account before Monday morning, the important check we wrote will bounce, leaving us in a very bad situation. And, of course, the bank is not open on Sunday. My wife reminds me of these facts. She then says, "Banks do change their hours. Do you know the bank will be open tomorrow?" Remaining as confident as I was before that the bank will be open then, still, I reply, "Well, no. I'd better go in and make sure." 
Ordinary speakers are supposed to intuit that the self-ascription of knowledge at the end of Low is true but that the self-ascription of ignorance at the end of High is also true. That is, ordinary speakers are supposed to see an important difference between these two cases, such that it would be correct to ascribe knowledge in the first case but ignorance in the second case.

The argument here depends on specific empirical claims regarding people's intuitions. Thus DeRose says of Low that "almost any speaker in my situation would claim to know the bank is open on Saturdays" (1992: 170). And he says of High that "Almost everyone will accept ["I don't know"] as a reasonable admission, and it will seem true to almost everyone" (1992: 170). Rysiew takes these cases to illustrate "a manifest flexibility in our willingness to attribute knowledge," holding it to be "incontrovertible that, in some sense anyway, 'what counts as knowing' depends upon 'context'." (2001: 477-8). Stanley motivates subject sensitive invariantism based in large part upon "the intuitive reactions we have about these cases" (2005: 5), explaining that his "central interest is to evaluate accounts that make as much sense of these intuitions as possible" (2005: 13). And Nagel presupposes such intuitions in asking "why our natural inclinations to ascribe knowledge become more stringent or lax when subjects are described as, for example, having pressing practical interests in the proposition believed" (2008: 279).

The existing debate is not so much about what intuitions people actually have in these cases, as it is about what significance these intuitions might have for the theory of knowledge. ${ }^{1}$ One view is that this pattern of intuitions provides support for the contextualist thesis that the truth conditions of knowledge ascriptions depend on conversational context. But there are other plausible alternatives. One might seek to explain the purported difference in intuitions between the cases while nonetheless rejecting the contexualist thesis. At least in part, the difficulty here stems from the fact that Low and High differ along at least two different dimensions, and rival philosophical theories can therefore explain the alleged differences in people's intuitions via different underlying factors.

First, Low and High differ over what is at stake for the subject. In Low it is "not especially important" that the checks be deposited before Monday morning. But in High we are told that the subject will be left in "a very bad situation" if the checks are not deposited before Monday morning. Note that this difference is not a matter of conversational context but rather of the actual circumstances of the subject to whom knowledge is being attributed, and it can therefore motivate theories that reject contextualism. This difference motivates subject-sensitive invariantism, according to which what is at stake for the subject plays a role in what the subject knows (Fantl and McGrath 2002; Stanley 2005). It also motivates a classical invariantist view according to which high stakes can undermine the attributor's own confidence in the proposition, and/or make her unwilling to attribute confidence in the proposition to the subject (Nagel 2008; Bach 2010). 
Second, Low and High differ over what possibilities are salient for the attributor (in these cases the attributor happens to be the same person as the subject, but these roles should still be distinguished). In High there is explicit mention of the possibility that the bank might change its hours ("Banks do change their hours"), while no such possibility is mentioned in Low. Such a difference motivates the contextualist thesis that what is salient to the attributor plays a role in the truth conditions for knowledge ascriptions (DeRose 1992; Cohen 1999). Such a difference also motivates a certain sort of classical invariantism, on which what is salient to the attributor plays a pragmatic role in the assertibility conditions for knowledge ascriptions (Rysiew 2001; Brown 2005).

Supposing (for the moment) that we do indeed attribute knowledge in Low and ignorance in High, given these two points of difference, "Low and High cannot show which difference is driving our intuitions" (Schaffer 2006: 88). To properly discern whether stakes or salience (or both, or neither) impacts our intuitions, one should use minimal pairs. That is, one should consider (i) a pair of cases which differ just over what is at stake for the subject, as well as (ii) a pair of cases which differ just over what is salient to the attributor. ${ }^{2}$

Claims about "what ordinary speakers will count as "knowledge"" (DeRose 2005: 72) are empirical claims, which can be tested. These claims are worth testing, for two reasons. First, given how crucial these claims are to the debate over contextualism, it is worth ensuring that our epistemological theorizing is not based on a myth. This is especially worth ensuring given the track record of empirical predictions from the armchair. Second, given that the central cases in the literature conflate stakes and salience, one can take the opportunity to introduce minimal pairs to remove this confound. This will allow one to differentiate the effects (if any) of stakes shifts from the effects (if any) of salience shifts.

Fortunately some of these tests already exist. There has been a recent wave of empirical research on these very matters, to which we now turn.

\section{Intuitions Surveyed}

In light of the importance of claims about our intuitions to the debate over contextualism, there has been a recent wave of empirical research testing these claims. This research suggests that ordinary speakers in fact attribute knowledge in both Low and High. It suggests that - contrary to what virtually all of the participants in the contextualism debate have supposed - neither stakes nor salience impacts the intuitions of ordinary speakers.

\subsection{Neta and Phelan}

Neta and Phelan (manuscript) conducted a study focused on the impact of stakes on people's intuitions about evidence. In particular they explored a thesis they called "anti-intellectualism about evidence," according to which 
one's evidence varies with what one has at stake. All participants in their study were given a story about a woman named Kate, who has some reason to think that she is on Main Street. Some participants received the following low stakes vignette:

Unimportant Kate is ambling down the street, out on a walk for no particular reason and with no particular place to go. She comes to an intersection and asks a passerby the name of the street. "Main Street," the passerby says. Kate looks at her watch, and it reads 11:45 AM. Kate's eyesight is perfectly normal, and she sees her watch clearly. Kate's hearing is perfectly normal, and she hears the passerby quite well. She has no special reason to believe that the passerby is inaccurate. She also has no special reason to believe that her watch is inaccurate. Kate could gather further evidence that she is on Main Street (she could, for instance, find a map), but she doesn't do so, since, on the basis of what the passerby tells her, she already thinks that she is on Main Street.

Other participants received a high stakes vignette, which was exactly the same as Unimportant, except that the first sentence was replaced by: 'Kate needs to get to Main Street by noon: her life depends upon it.'

Participants in the study were then asked how confident Kate should be that she actually was on Main Street. ${ }^{3}$ The results failed to reveal any impact of stakes on these judgments. Participants in the low stakes and high stakes conditions arrived at almost exactly the same conclusion about how confident Kate should be. Such results cast doubt on any claim that our intuitions about evidence support anti-intellectualism.

Interestingly - though this is not a matter we will attempt to explainNeta and Phelan did find a different pattern of responses in a within subjects condition on which participants got to contrast a low stakes and a high stakes situation. In this alternative experimental design, participants can easily see that the only difference lies in the stakes, and they can then consciously reflect on whether this difference in stakes should lead to a difference in confidence. Participants in this condition showed a significant and substantial tendency to say that Kate should have lower confidence where the stakes are high than where the stakes are low.

Drawing on these and other related results, ${ }^{4}$ Neta and Phelan propose a new hypothesis about the role of stakes in people's intuitions about evidence. They suggest that stakes actually do not figure at all in the purely tacit mechanism people ordinarily use to make judgments about evidence, but that when people reflect on these questions in a more abstract, philosophical way, some of them end up concluding that evidence does vary with changes in stakes. Neta and Phelan (personal communication) point out that their hypothesis can be captured in the slogan: 'Only intellectuals are anti-intellectualist.'

Neta and Phelan's studies certainly cast doubt on claims that our intuitions about evidence are anti-intellectualist. But their results fall short of 
what we are looking for, in two main ways. (This is not a criticism of Neta and Phelan.) First, their studies did not ask participants about knowledge. Instead, they posed questions about rational confidence (which they take as proxy for evidence). Second, Neta and Phelan only explore the prospects of a stakes-based effect on our intuitions. They do not explore the prospects of a salience-based effect.

\subsection{Feltz and Zarpentine}

Feltz and Zarpentine (forthcoming) conducted a series of studies focused on the impact of stakes on people's intuitions about knowledge. They began with a range of bank cases, drawn verbatim from Stanley 2005. They found no statistically significant difference in responses between the low stakes and high stakes cases. That is, participants were not significantly more inclined to agree in the low stakes case than they were in the high stakes case. ${ }^{5}$

Feltz and Zarpentine also worried that the bank cases confound stakes and salience $(\S 1)$, so they wisely moved to minimal pairs that differ solely over stakes:

Simplified High Stakes Hannah and her sister Sarah are driving home on a Friday afternoon. They plan to stop at the bank on the way home to deposit their paychecks. Since they have an impending bill coming due, it is very important that they deposit their paychecks by Saturday. Hannah notes that she was at the bank two weeks before on a Saturday morning, and it was open. Hannah says to Sarah, 'I know that the bank will be open tomorrow'.

Simplified Low Stakes Hannah and her sister Sarah are driving home on a Friday afternoon. They plan to stop at the bank on the way home to deposit their paychecks. Since they do not have an impending bill coming due, it is not very important that they deposit their paychecks by Saturday. Hannah notes that she was at the bank two weeks before on a Saturday morning, and it was open. Hannah says to Sarah, 'I know that the bank will be open tomorrow'.

They found no statistically significant difference in responses to these cases, nor did they find statistically significant differences in responses to analogous cases involving trucks crossing rickety bridges (in the low stakes case the bridge is over a three foot ditch, while in the high stakes case the bridge is over "a yawning thousand foot drop").

Feltz and Zarpentine's results go beyond Neta and Phelan's results in one of the two main ways we are looking for. For Feltz and Zarpentineunlike Neta and Phelan - did pose questions about knowledge. But Feltz and Zarpentine are still focused on stakes-based effects, and did not explore the prospects of a salience effect. That is, they did not consider minimal pairs that differ only over what is salient to the attributor, which are the crucial support cases for a contextualist semantics. 


\subsection{May, Sinnott-Armstrong, Hull, and Zimmerman}

May, Sinnott-Armstrong, Hull, and Zimmerman (2010) conducted a study that examined the impacts of stakes and of salience on questions about knowledge (which was what we were looking for). Each participant in their study was given a bank case. May et al. then systematically manipulated whether or not it was important for the subject to get the money deposited quickly (the stakes), and whether or not it was mentioned that banks sometimes change their hours (the salient alternative). Thus, participants were randomly assigned to receive one of four possible cases:

\begin{tabular}{ll}
\hline & No Alternative Alternative \\
\hline Low Stakes & \\
High Stakes & \\
\hline
\end{tabular}

Within each of these cases, participants were asked how much they agreed or disagreed with the statement: 'Hannah knows that the bank will be open on Saturday.' Participants indicated their level of agreement on a scale from 1 ('disagree') to 7 ('agree'). The results came out as follows:

\begin{tabular}{lcc}
\hline & No Alternative & Alternative \\
\hline Low Stakes & 5.33 & 5.30 \\
High Stakes & 5.07 & 4.60 \\
\hline
\end{tabular}

In all four cases, the mean agreement was above the midline ( $>4)$, indicating an overall positive tendency to knowledge ascription in every case. Further statistical analysis revealed no significant effect of manipulating the alternative. There was a very small effect of manipulating the stakes, which managed to just squeak past the conventional threshold of statistical significance $(p=.04)$.

Thus May et al.'s results suggest that ordinary speakers attribute knowledge in bank cases, regardless of stakes or salience. The most that seems to vary with the stakes is a marginal degree of confidence in this knowledge attribution.

That said, some contextualists might object to the experimental design used by May et al. Participants were given a story about a conversation and then asked whether one of the characters in that story had knowledge. But some contextualists might object that manipulating the conversation in the story need not affect the knowledge ascriptions that participants in the study are prepared to make, since the participants are not themselves speaking within the context provided by the conversation in the story (DeRose personal communication). 


\subsection{Buckwalter}

Buckwalter (2010) conducted a study using a design that was very similar to the one employed by May et al, but which avoided the potential contextualist objection just mentioned. In Buckwalter's study, participants were given a vignette in which one of the characters actually makes a knowledge ascription. Then, instead of being asked directly whether a particular person had knowledge, they were asked whether the knowledge ascription made by the character in the vignette was true or false. This design helps to ensure that participants are judging the knowledge ascription within the conversational context described in the vignette itself.

Participants in Buckwalter's study were randomly assigned to one of three conditions. In the first condition, there were low stakes and no mention of error possibilities:

Baseline Sylvie and Bruno are driving home from work on a Friday afternoon. They plan to stop at the bank to deposit their paychecks, but as they drive past the bank they notice that the lines inside are very long. Although they generally like to deposit their paychecks as soon as possible, it is not especially important in this case that they be deposited right away. Bruno tells Sylvie, "I was just here last week and I know that the bank will be open on Saturday." Instead, Bruno suggests that they drive straight home and return to deposit their paychecks on Saturday. When they return to the bank on Saturday, it is open for business.

Then there was a second condition in which the third sentence was changed to make it clear that there were high stakes:

Bruno has written a very large check, and if the money from his pay is not deposited by Monday, it will bounce, leaving Bruno in a very bad situation with his creditors.

Finally, there was a condition in which the third sentence was left as in the original, but the following sentences were added after the fourth sentence, in an attempt to increase the salience of error possibilities:

Sylvie says, "Banks are typically closed on Saturday. Maybe this bank won't be open tomorrow either. Banks can always change their hours, I remember that this bank used to have different hours."

In all three conditions, participants were asked to indicate "how much you agree or disagree that Bruno's assertion 'I know the bank will be open on Saturday' is true."

The study showed no significant effect either of stakes or of the salience of error possibilities. Instead, subjects in all three conditions showed a tendency to agree that Bruno's self-ascription of knowledge was true. ${ }^{6}$ 


\subsection{Beebe and Buckwalter}

Before moving onward, we want to discuss one final experimental study. This last study does not look directly at the impact of either stakes or salience but rather considers the effect of moral valence on knowledge ascriptions.

On the one hand it might seem surprising to look for moral valence effects on knowledge ascriptions, since none of the leading epistemological theories (contextualist or invariantist) directly predicts that moral valence should play any role. But on the other hand, recent research in experimental philosophy suggests that moral considerations can impact people's intuitions in a surprisingly wide variety of domains - including intentional action, causation, the doing/allowing distinction, and act individuation (Knobe 2003; Hitchcock and Knobe forthcoming; Cushman et al 2008; Ulatowski 2008; Pettit and Knobe 2009). So one might well expect that this sort of effect might arise with knowledge ascriptions too.

And so Beebe and Buckwalter (2010) conducted a study looking for moral valence effects on knowledge ascriptions. Participants in their study were randomly assigned either to the harm condition or to the help condition. Those in the harm condition received the following vignette:

$\underline{\text { Harm }}$ The vice-president of a company went to the chairman of the board and said, "We are thinking of starting a new program. We are sure that it will help us increase profits, but it will also harm the environment." The chairman of the board answered, "I don't care at all about harming the environment. I just want to make as much profit as I can. Let's start the new program." They started the new program. Sure enough, the environment was harmed.

These participants were then asked: 'Did the chairman know that the new program would harm the environment?'

Participants in the help condition received a vignette that was almost exactly the same, except that the moral status of the chairman's behavior was changed by replacing all instances of the word 'harm' with 'help.' Participants in this latter condition were then asked: 'Did the chairman know that the new program would help the environment?'

This change in moral status triggered a change in people's willingness to say that the chairman had knowledge. Although more than half of the participants in both conditions said that the chairman did have knowledge, there was a statistically significant effect whereby participants were more inclined to ascribe knowledge in the harm condition than they were in the help condition. ${ }^{7}$

\subsection{Summary and Options}

The empirical trend seems in one sense clear and in another sense confusing. What seems clear is that neither stakes nor salience has much if any impact on people's intuitions about knowledge. Though the various researchers varied 
the details of the stimuli and the experimental design, ordinary speakers seem to attribute knowledge regardless of stakes or salience, with roughly the same level of confidence. And so it seems as if the current debate over contextualism - or at least that portion of it premised on claims about 'our intuitions' in bank cases - is based on a myth.

What seems confusing is why moral valence should have an impact on people's responses to questions about knowledge. This is an effect directly predicted by none of the standard contextualist or invariantist theories, and yet it is the only effect that was actually observed! What is going on?

There seem to us to be three main options going forward. First, one could simply reject the experimental method. But if one is interested in the intuitions of ordinary speakers (as per the current contextualism debate: $\S 1$ ), then one needs to have some way of figuring out which intuitions people actually have in particular cases. Of course, one cannot simply assume that people's intuitions always correspond perfectly to the responses they give in experimental studies, but it does seem that the best way to get at the truth about people's intuitions is to start from the available data and then do one's best to construct an empirically-supported theory. ${ }^{8}$

Second, one could accept the method but reject the interpretation of the data. This would require an explanation of why, even though our concept of knowledge is 'really' stakes or salience sensitive (or 'really' moral valence insensitive), the surveys we have reviewed came out 'as if' otherwise. This explanation should have independent psychological plausibility, and should in principle (and hopefully in practice) be subject to further empirical test.

Third, one could accept the method and the interpretation of the data. This would presumably require a new view of our concept of knowledge, with the following two features. First, the view would have to start off looking a lot like classical invariantism, in the tradition running through Moore (1959) and Chisholm (1977). After all, it is characteristic of such a classical invariantist position to admit fallible knowledge, unaffected by what is at stake for the subject or what is salient for the attributor. The data on bank cases seem to reveal that our concept of knowledge has this character. But second, the view would have to add moral sensitivity, to account for the Beebe and Buckwalter data. It would then be a nice question as to whether the theory could remain invariantist or would need to turn contextualist.

We think that there is significant pressure towards taking the second of these three options. Or at least, those who accept the relevance of experimental data to empirical claims about our intuitions, and those who accept any of the existing theories of knowledge, must take the second option in some form. So we think that the overall most plausible approach would be to try to reconcile the empirical data with existing theory.

Accordingly we will be taking the second option. In particular, we will try to reconcile the empirical data with a specific form of contextualism. We accept the interpretation of the data on which stakes have little to no impact 
on knowledge ascriptions, and we accept the interpretation on which moral valence does impact knowledge ascriptions. But we want to challenge the interpretation on which salience has no impact. Indeed, we will be offering new data that will show a salience effect, in a way which will allow us to explain why the previous studies failed to observe this effect. In short, we will be arguing that there is a specific version of contextualism that fits all the data.

\section{Contrastive Knowledge}

So far we have displayed the importance of claims about our intuitions to the contextualism debate $(\S 1)$, and reviewed the recent wave of empirical research calling these claims into doubt (§2). We will now sketch our theoretical framework, and present our results.

\subsection{The Moral Valence Effect as a Contrast Effect}

We begin with the moral valence effects (found by Beebe and Buckwalter: $\S 2.5)$, as we think that these help point the way forward. Why is it that changing the moral status of the chairman (from hurting to helping the environment) should change people's willingness to say that the chairman has knowledge?

Our hypothesis will be that this effect arises because of a change in contrast. Here we rely on the documented connection, confirmed in a number of experimental studies, between people's moral judgments and their intuitions about which contrasts are relevant (Hitchcock and Knobe forthcoming; McCloy and Byrne 2000; N'gbala and Branscombe 1995). To illustrate, consider the case of moral judgments about race relations. If people feel that a given racial group is being unjustly oppressed, their thoughts will usually be drawn spontaneously to the alternative in which this racial group is treated more justly. However, if people feel that a given racial group is being treated justly, they will not usually find themselves spontaneously imagining a contrast in which this racial group is treated less justly. Thus, if someone asks us to imagine a world in which African Americans are no longer oppressed, we will immediately see why this possibility is worth considering, but if someone simply says 'Imagine a world in which only brown-eyed people are allowed to go to public bathrooms,' we may initially feel confused and might even ask our interlocutor: 'Why exactly should we imagine that?'

The basic principle runs as follows. If people take a behavior to be morally bad, they tend to regard alternatives in which that behavior is replaced by something morally good as being especially relevant. Whereas if people take a behavior to be morally good, they tend not to regard contrasts in which this behavior is replaced with something morally bad as being especially relevant. Hence, when people consider a given case, their moral judgments 
have an impact on which contrasts they consider (Hitchcock and Knobe forthcoming).

We now have the materials needed for a contrastive explanation of the moral valence effects. Given that people's moral judgments affect the contrasts they consider, people's moral judgments may affect which knowledge ascriptions they regard as true because the truth of a knowledge ascription is sensitive to which contrasts are considered. Or to put the point in the form of a prediction: given that people's moral judgments affect the contrasts they consider, if the truth conditions for knowledge ascriptions are sensitive to which contrast the ascriber considers, then people's moral judgments should have the potential to affect which knowledge ascriptions they regard as true.

Let us apply these ideas to the Beebe and Buckwalter cases. The case where the chairman hurts the environment is a case where an agent performs an immoral behavior. So there will be a natural tendency to consider the contrast in which the chairman does not perform that behavior at all. And so, when participants consider the question 'Did the chairman know that the new program would harm the environment?', we expect that they will primarily consider the morally good alternative in which the new program goes unadopted.

If we add the further supposition that knowledge requires something like the elimination of relevant alternatives ( $\$ 3.2)$, then we can see why subjects would be quite willing to ascribe knowledge in this case. The chairman presumably can tell that he has already decided to adopt the new program. So he can on this basis rule out the relevant alternative in which the new program goes unadopted. Thus people should be inclined to attribute knowledge to him.

In the case where the chairman helps the environment, there is no immoral behavior. So there will be less of a natural tendency to consider the contrast in which the chairman does not perform the behavior at all. And so, when participants consider the question 'Did the chairman know that the new program would help the environment?', we expect that they will primarily consider other alternatives. In this particular case, we expect that they will have a greater tendency to consider the alternative in which the new program gets adopted but winds up unexpectedly not helping the environment.

If we keep the supposition that knowledge requires something like the elimination of relevant alternatives, then we can see why subjects would be less willing to ascribe knowledge in this case. The chairman has only the voiced assurance of the vice-president on the matter of environmental impact, and this bit of testimony might be regarded as insufficient. (At any rate, this bit of testimony should clearly be regarded as having a lesser evidential status than the chairman's own awareness of his immediate intentions.) So it is less clear that the chairman can rule out the relevant alternative in which the new program has unexpected non-helpful environmental consequences. Thus people should be less inclined to attribute knowledge. ${ }^{9}$ 
We would emphasize that we have offered just one possible explanation of the moral valence effect on knowledge ascriptions, via a moral valence effect on relevant contrasts, together with a contrast sensitive view of the truth conditions for knowledge ascriptions. We consider this explanation promising, but acknowledge that further research may lead to the development of quite different hypotheses. ${ }^{10}$ We will now develop and defend a model on which contrasts play a crucial role in our knowledge ascriptions. If the moral valence effects prove to be best explained in a different way, then they will at least have provided us with a ladder to be kicked away.

\subsection{A Contrastive Model}

We propose a model on which our intuitions about knowledge are contrast sensitive. On this model, our concept of knowledge is a contrastive concept. Knowledge so conceived is not a two-place relation between a subject and proposition, but is rather a three-place relation between a subject, a proposition (the fact), and a contrast proposition (the foil). All knowledge takes the form: $s$ knows that $p$ rather than $q .{ }^{11}$

The contrastive view can be seen as a direct implementation of a classic relevant alternatives view of knowledge (c.f. Austin 1946). The relevant alternatives view holds that whether $s$ knows that $p$ depends on which alternatives to $p$ are relevant. On the contrastive view, these relevant alternatives show up as an additional third argument of the knowledge relation. Such a view emerges in the following passage from Dretske: "To know that $x$ is $A$ is to know that $x$ is $A$ within a framework of relevant alternatives, $B, C$, and $D$. This set of contrasts ... serve to define what it is that is known ..." (1970: 1022). ${ }^{12}$

The contrastive view can also be seen as a version of contextualism. This is because the contrastive view allows that one ascriber could truly say " $s$ knows that $p$," while a second ascriber in a second context (with a different range of relevant alternatives) could truly deny "s knows that $p$." This is because the first ascriber could truly express the proposition that $s$ knows that $p$ rather than $q 1$, while the second ascriber could truly deny $s$ knows that $p$ rather than $q 2 .{ }^{13}$

There are two key aspects of the contrastive model that we would emphasize here. The first is that our concept of knowledge is regarded as including a contrast argument. The second-which continues to follow the contours of the classical relevant alternatives view-is that our concept of knowledge is regarded as requiring the elimination of the contrast. To know that $p$ rather than $q$ requires ruling out $q$. And so if $s$ can rule out $q 1$ but not $q 2$, then $s$ might know that $p$ rather than $q 1$, but $s$ cannot know that $p$ rather than $q 2$.

\subsection{Predictions of the Contrastive Model}

The contrastive model looks to predict a moral valence effect, when coupled with the further (empirically plausible) claim that moral valence affects which 
alternatives are regarded as relevant ( $\$ 3.1)$. The contrative model does not predict any stakes effect. ${ }^{14}$ So far, so good.

But the contrastive model does predict a salience effect, which brings it into conflict with the lack of any observed salience effect in the May et al and Buckwalter studies ( $\S \S 2.3-2.4)$. After all, contrastivism is a direct implementation of a relevant alternatives view. On the contrastive model, the truth conditions for sentences of the surface form " $s$ knows that $p$ " depend on the value assigned to the implicit argument for the contrast (the ' $q$ ' in ' $s$ knows that $p$ rather than $q$ '). The value assigned to this argument will turn on which alternatives are relevant. In this way, conversational context can affect the contrast. Thus contrastivism sails in the same (seemingly leaky) boat as contextualism. ${ }^{15}$

Overall, the contrastive model issues the following predictions (where the top row lists potential factors impacting knowledge ascription, and the bottom row says whether any impact is predicted):

Contrast of the Ascriber Salience for the Ascriber Stakes for the Subject

Yes Yes No

Strictly speaking, the contrast effect and the salience effect are independent. One could have a contrast effect, but deny that the contextual salience of an alternative can help to set the contrasts. Or one can maintain a salience effect, but deny that it operates through helping to set the contrasts. Indeed some alternative contextualist theories maintain this latter claim ( $(6.4)$. So it is worth separating these effects. The contrastive model treats the salience effect as an indirect contrast effect, but not all models share this treatment.

Yet the data so far gathered suggest the following pattern:

Contrast of the Ascriber Salience for the Ascriber Stakes for the Subject

? No No

So our first agenda-especially in light of the surprising empirical results in the bank cases - is to gather empirical evidence with respect to contrast sensitivity. This will serve as our argument that the "?" in the leftmost column should be replaced by a "Yes." Our second agenda-given the lack of any observed salience effect in the May et al and Buckwalter studies-is to provide an empirically supported explanation for what went wrong in these studies, and show that there is a real salience effect when the studies are done properly. This will serve as our argument that the "No" in the middle column should be replaced by a "Yes." (The "No" in the rightmost column 
we take to be already supported by the existing data: $\S 2$ ). This is what it will take to vindicate the contrastive model, if the model can be vindicated.

\section{Empirical Evidence of a Contrast Effect}

Our first agenda is to seek better empirical evidence with respect to the contrast sensitivity of knowledge ascriptions. With this in mind, we looked at three different ways of manipulating the contrast, involving (i) the use of overt "rather than" phrases, (ii) the use of knowledge-wh constructions, and (iii) the use of questions prior to simple " $s$ knows that $p$ " constructions. We found - in accord with the contrastivist prediction - a unified pattern of shifts in responses across these three different ways of manipulating contrasts.

\section{1 "Rather than"}

Our first study involved manipulating "rather than" phrases. To explain how this study worked, let us first introduce a simple story, which we will call the jewel thief vignette:

Last night, Peter robbed the jewelry store. He smashed the window, forced open the locked safe, and stole the rubies inside. But Peter forgot to wear gloves. $\mathrm{He}$ also forgot about the security camera.

Today, Mary the detective has been called to the scene to investigate. So far she has the following evidence. She has been told that there was a theft, she has found and identified Peter's fingerprints on the safe, and she has seen and recognized Peter on the security video, filmed in the act of forcing open the safe. She has no further information.

Notice that this story is constructed in such a way that Mary's evidence allows her to eliminate certain possibilities but not others. Specifically, her evidence allows her to rule out the possibility that (a) someone other than Peter was the thief, but it does not allow her to rule out the possibility that (b) Peter stole something other than the rubies. Given all this, one might well pose the question: 'Does Mary know that Peter stole the rubies?'

If contrastivism is correct, matters here are more complex than they might seem. One cannot simply pick out a proposition and ask whether someone knows it. One must specify the relevant contrast. Thus, if $q 1$ and $q 2$ are two distinct contrast propositions, it might turn out that Mary does know that Peter stole the rubies rather than ql but does not know that Peter stole the rubies rather than $q 2$.

To determine whether people's responses show this contrast sensitive pattern, we conducted a simple experiment. All participants were given the jewel thief vignette. However, each participant was randomly assigned to one of two conditions. Participants in the thief contrast condition were asked whether they agreed or disagreed with the statement: 
Mary now knows that Peter rather than anyone else stole the rubies

Meanwhile, participants in the jewel contrast condition were asked whether they agreed or disagreed with the statement:

Mary now knows that Peter stole the rubies rather than anything else.

Participants rated these sentences on a scale from 1 ('disagree') to 7 ('agree'). The results showed a striking difference in responses between the two conditions. Participants in the thief contrast condition tended to agree with the knowledge ascription they received (mean rating: 4.6), while participants in the jewel contrast condition tended to disagree with the knowledge ascription they received (mean rating: 3.1 ). This difference was statistically significant. ${ }^{16}$

A question now arises as to why people's responses showed this difference between conditions. Our hypothesis is that the effect is due to a difference in contrasts. That is, we propose that the two conditions of the experiment involve ascribing knowledge of the very same proposition and that they differ only in that they pick out two different contrasts to that proposition. But we recognize that other interpretations are possible. ${ }^{17}$ Perhaps we are mistaken in our assumptions about the role of "rather than" clauses, and the two conditions of our experiment actually differ on some other relevant dimension. Our next step, therefore, is to seek converging evidence for the contrastivist hypothesis. We will proceed by looking at a series of different ways of manipulating contrasts and showing a uniform impact on people's responses.

\subsection{Knowledge-wh}

For our second study, we turned away from knowledge-that constructions with "rather than" phrases, and looked instead at certain knowledge-wh constructions. That is, instead of looking at constructions of the form 'She knows that...,' we looked at constructions like 'She knows who...' or 'She knows what...'

For present purposes, the key thing to note about such constructions is that they pick out both a particular proposition and a contrast. Thus, consider the knowledge-wh construction:

Mary knows who stole the rubies.

If one were asked to explain what exactly Mary needs to know to satisfy this ascription, one might initially be tempted to say something like: 'Well, she needs to know that Peter stole the rubies.' But it seems that this construction is doing more than just picking out that one proposition; it is also picking out a field of relevant alternatives. In this case, we might more accurately capture 
that contrast information by saying that Mary only satisfies the ascription if she knows that it was specifically Peter (rather than anyone else) who stole the rubies. $^{18}$

This fact about contrasts comes out especially clearly if we turn for comparison to a second knowledge ascription:

Mary knows what Peter stole.

Though this second ascription looks very different from the first, it appears to attribute to Mary knowledge of precisely the same proposition, namely the proposition that Peter stole the rubies. Yet the contrast has now changed radically. In explaining this latter ascription, we might say that Mary can satisfy it only if she knows that Peter specifically stole the rubies (rather than anything else).

We now have a new opportunity to put contrastivism to the test. If knowledge were simply a relation between a person and a proposition, all these differences in contrasts should have no effect on the truth values of the knowledge ascriptions themselves. Ultimately, the whole issue would just come down to whether or not Mary stood in the right sort of relation to the proposition that Peter stole the rubies. If she did, both knowledge ascriptions would be true; if not, both would be false. On the other hand, if contrastivism is correct, these differences in contrast can actually make a difference to the truth values of the knowledge ascriptions. Since the two knowledge ascriptions discussed here pick out two different contrasts, it can turn out that one of them is true and the other false.

To determine whether people's responses in these cases are sensitive to such differences in contrast, we conducted a second experiment. Once again, all participants were given the jewel thief vignette, and each participant was randomly assigned to one of two conditions. This time, participants in the thief contrast condition were asked whether they agreed or disagreed with the sentence:

Mary knows who stole the rubies.

And participants in the jewel contrast condition were given the sentence:

Mary knows what Peter stole.

As in the previous experiment, participants rated these sentences on a scale from 1 ('disagree') to 7 ('agree').

Again, the results showed a marked difference between conditions. Participants in the thief contrast condition tended to agree with the statement that Mary knew who stole the rubies (mean rating: 4.91), while participants in the jewel contrast condition tended to disagree with the statement that Mary 
knew what Peter stole (mean rating: 2.62). This difference was statistically significant. ${ }^{19}$

We have now reported results from two separate experiments, using two quite different ways of manipulating contrasts. Both show the same basic effect. It seems that specifying a contrast within the words of a knowledge ascription itself truly does have an impact on people's intuitions as to whether that knowledge ascription is true or false.

\subsection{Context Sensitivity}

So far we have considered cases where the contrast is explicitly specified within the knowledge ascription. But of course there are also knowledge ascriptions without any explicitly specified contrast, such as: 'Mary knows that Peter stole the rubies.' How are we to make sense of knowledge ascriptions of this form?

It is here that conversational context plays its crucial role. Our suggestion will be that when the contrast is not stated explicitly in the words of the knowledge ascription itself, people look instead to information from the conversational context. Hence, in these latter cases, people are using the conversational context to fill in precisely the same sorts of information that, in the cases we discussed above, were filled in by the actual words of the knowledge ascription. ${ }^{20}$

Notice the form of the argument here. We are not simply invoking contrasts as a way of making sense of the effects of context. Rather, we began by exploring the role of contrasts using pairs of cases that manipulated the actual wording of the knowledge ascription itself. Then, with the basic contrastivist framework already in place, we went on to hypothesize that people sometimes look for contrast information in the conversational context. We can now conduct a new experimental study to test that new hypothesis.

To do so, we tried to create a set of stimuli that mirrored our two earlier experiments as closely as possible, except that contrast was manipulated using conversational context alone, by manipulating the question under discussion. All participants received the very same jewel thief vignette used in the two prior studies. Participants in the thief-contrast condition then read:

Everyone is now asking the big question: Who stole the rubies? The news reporter is about to write a story about Mary. He is wondering if Mary now knows who stole the rubies. He writes: "Mary now knows that Peter stole the rubies."

Please tell us whether you agree or disagree with the news reporter's claim, "Mary now knows that Peter stole the rubies."

Participants in the jewel-contrast condition instead read: 
Everyone is now asking the big question: What did Peter steal? The news reporter is about to write a story about Mary. He is wondering if Mary now knows what Peter stole. He writes: "Mary now knows that Peter stole the rubies."

Please tell us whether you agree or disagree with the news reporter's claim, "Mary now knows that Peter stole the rubies."

The results showed the usual difference between conditions. Participants tended to agree with the knowledge attribution in the thief-contrast condition (mean rating: 5.24 out of 7) but to disagree with the knowledge attribution in the jewel-contrast condition (mean rating: 2.97 out of 7). This difference was statistically significant. ${ }^{21}$

In short, the pattern of responses in this case where we manipulated conversational context was almost exactly the same as the pattern observed in the two earlier cases where we manipulated the actual words of the knowledge ascription itself:

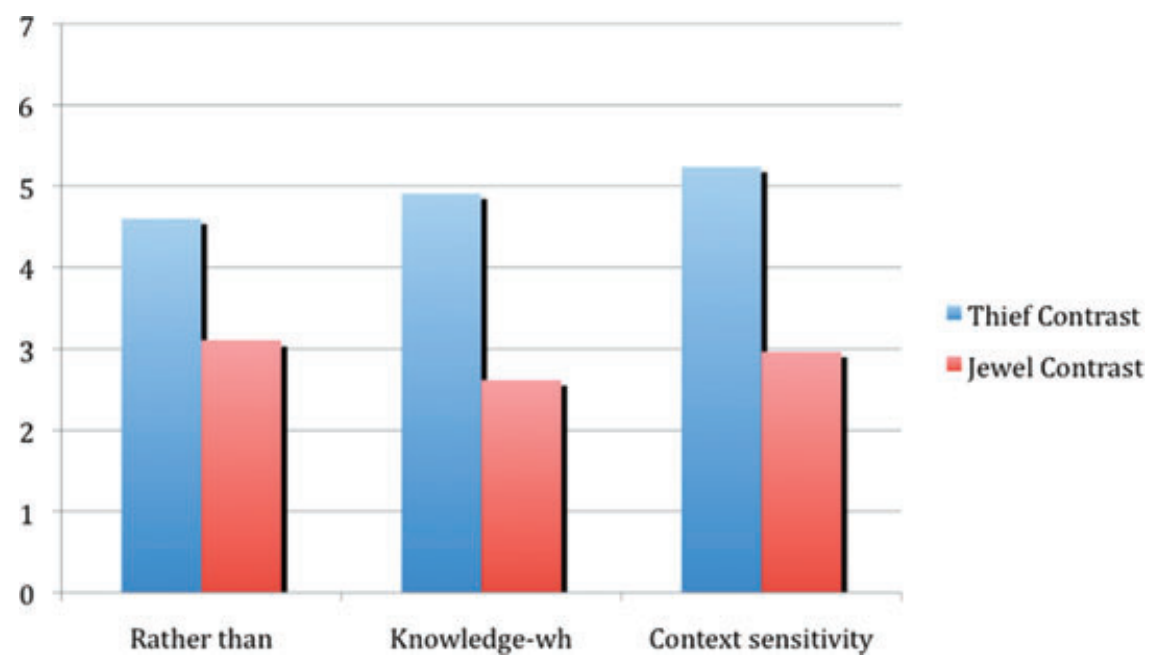

A natural hypothesis, then, would be that the effect of conversational context in this case should be understood using precisely the same framework one would use to understand the effect of the wording in the two earlier cases. Overall, the contrastive framework seems to provide a natural and uniform explanation for our uniform pattern of results.

\section{Empirical Evidence of a Salience Effect}

Our second agenda is to explain away the seeming lack of salience effects observed in the May et al and Buckwalter studies (§§2.3-2.4), in an empirically supported way. For one might think that these studies already show that 
our intuitions are not contrast sensitive. After all, it seems that these studies specifically introduced as a contrast the possibility that the bank might have changed its hours, and failed to observe any significant effect of this contrast on people's responses.

We take this to be a serious and important objection. The bank cases have been constructed in such a way that the characters in the story do not have sufficient evidence to rule out the possibility that the bank has changed its hours. If one could create a conversational context in which it was clear that the relevant contrast involved the bank changing its hours, then, by the lights of contrastivism, it should be false to attribute knowledge in this context. Yet the existing experimental studies clearly show that people's willingness to claim knowledge in such cases is not affected by the mention of this error possibility. How do we explain this?

Our answer here may come as a surprise. We want to suggest that existing experimental studies simply have not succeeded in manipulating the conversational context so as to make the bank changing its hours the relevant contrast. The existing studies merely mention the possibility of a change in hours. But merely mentioning a possibility need not render it salient. In particular, the possibility of a bank suddenly changing its hours is a strange and improbable one, and it might not be possible to make people regard it as relevant merely by mentioning it once in the course of a vignette. Perhaps one can only make people regard a possibility as salient by presenting it in a concrete and vivid fashion.

Indeed, there is independent psychological evidence that mentioning a possibility in an abstract and pallid manner can actually depress salience. In this vein, Oppenheimer (2004) shows that people spontaneously discount recognition as a sign of likelihood, when they are aware of another plausible explanation for recognition. And Sherman et al (1985) show that asking people to imagine a peculiar and abstract scenario will make them regard that scenario as less likely. As Nagel summarizes this and related data: "[S]pontaneous discounting in the face of explicit mention occurs across a number of types of judgment" (2010: 297).

To test the hypothesis that May et al and Buckwalter had presented the possibility of the bank changing its hours in too abstract and pallid a manner to make it salient, we conducted one final study. Our idea was to follow May et al and Buckwalter as closely as possible by using a bank case, but this time making the possibility of the bank changing its hours concrete and vivid, by using a personal anecdote invested with emotional force. Participants in this study were randomly assigned either to the control condition or to the salient contrast condition. Participants in the control condition received a simple bank case:

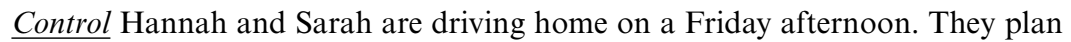
to stop at the bank to deposit their paychecks. As they drive past the bank, 
they notice that the lines inside are very long, as they often are on Friday afternoons.

Hannah says, "I was at the bank two weeks before on a Saturday morning, and it was open. So this is a bank that is open on Saturdays. We can just leave now and deposit our paychecks tomorrow morning."

Sarah replies, "Ok, that sounds good. Let's go on Saturday."

Participants in the salient contrast condition received a vignette that was exactly the same, except that Sarah's response brings out the idea of a bank changing its hours in an especially concrete and vivid way (through a personal anecdote invested with emotional force):

Sarah replies, "Well, banks do change their hours sometimes. My brother Leon once got into trouble when the bank changed hours on him and closed on Saturday. How frustrating! Just imagine driving here tomorrow and finding the door locked."

All participants were told to suppose that 'Hannah stays just as confident as she was that the bank will be open on Saturday.' They were then asked to rate the degree to which they agreed or disagreed with the attribution: 'Hannah knows that the bank will be open on Saturday.'

Strikingly, when the error possibility was made concrete and vivid in this way, the results did reveal a salience effect, just as all the contextualist models - including the contrastive model-predict. Participants in the default condition tended to agree with the knowledge attribution (mean rating: 5.54 out of 7), while participants in the salient alternative condition tended to disagree (mean rating: 3.05 out of 7 ). This difference is statistically significant. ${ }^{22}$

One nice consequence of finding a salience effect is that we need no longer dismiss the intuitions of the epistemologists as theory driven or otherwise defective. For it does seem clear that a wide range of epistemologists, with various theoretical predilections, agreed about the bank cases. We speculate that the main difference between ordinary speakers and trained epistemologists is that the epistemologists needed less prodding to view the error possibility as salient.

The data and discussion of the previous two sections complete our two part agenda. We have found direct positive evidence for contrast sensitivity $(\S 4)$, and explained away the seeming lack of salience effects in previous studies while showing that there is a real salience effect $(\S 5)$. Recall that the prediction generated by the contrastive model was as follows ( $\{3.3)$ :

\begin{tabular}{lcc}
\hline Contrast of the Ascriber & Salience for the Ascriber & Stakes for the Subject \\
\hline Yes & Yes & No \\
\hline
\end{tabular}


The empirical evidence, properly understood, turns out to be exactly as predicted. In this respect at least, the contrastive model has been vindicated.

\section{Alternative Models}

The key question that remains is whether any other model can do as well in explaining the data. We will now turn to invariantist models, and then to other contextualist models, to see how they compare. If they cannot compare, then contrastivism can lay claim to providing the best explanation for our intuitions.

By an 'invariantist model' we mean any model that disallows the prospect that one ascriber could truly say " $s$ knows that $p$," while a second ascriber in a second context could truly deny " $s$ knows that $p$ " (where these two ascribers are speaking of the same subject $s$ and proposition $p$, at the same world and time). Our question now is whether any such models successfully predict the above data table.

We should acknowledge from the start that this is a very difficult question, since the linguistic behavior observed is not purely generated by the semantics of a term or our conceptual competence, but can be influenced by conversational pragmatics and distorted by performance errors. Accordingly we will proceed as follows. We will first consider the predictions of the invariantist models themselves. Then - where discrepancies arise between predictions and data - we will consider pragmatic and performance based explanations for these discrepancies.

\subsection{Subject Sensitive Invariantist Models}

We will start by considering subject sensitive invariantist models, which are invariantist models in which what is at stake for the subject (real or perceived) is predicted to play a role in the truth of knowledge ascriptions. These models predict that the higher the stakes for the subject, the lower the propensity for the ascriber to ascribe knowledge (all else equal). ${ }^{23}$ Such models themselves (unsupplemented by pragmatic or performance based factors) seem to predict the exact opposite of the data. That is, such models seem to predict the following pattern:

\begin{tabular}{lcc}
\hline Contrast of the Ascriber & Salience for the Ascriber & Stakes for the Subject \\
\hline No & No & Yes
\end{tabular}

This pattern of predictions is no accident. Subject sensitive invariantist theories arose on the one hand from a rejection of contextualist theories. Hence the prediction of no contrast or salience effects. And these theories arose on the other hand from the thought that the alleged pattern of 
intuitions in contextualist bank cases could be explained in non-contextualist terms, via shifts in what is at stake for the subject ( $§ 1)$. Hence the prediction of stakes effects. We thus take the data observed to present a strong prima facie challenge to the plausibility of subject sensitive invariantist models of knowledge ascriptions.

That said, a subject sensitive invariantist model could in principle be coupled with heavy invocation of pragmatic influences or performance errors, so as to reverse the predictions in every case. A model of our conceptual competence that predicts the exact opposite of the data might seem to be off to an unpromising start, but there are independent motivations for the subject sensitive model in the literature that are not directly tied to claims about the intuitions of ordinary speakers. ${ }^{24}$ So all in all we think of the data as providing a strong prima facie challenge to subject sensitive invariantist models, not as providing a refutation. We see the defender of the subject sensitive model as taking on the burden of providing a pragmatic or performance based story. We will consider the prospects for such a story below (§6.3).

\subsection{Classical Invariantist Models}

The classical invariantist models are invariantist models that do not predict that the stakes for the subject should impact the truth conditions for knowledge ascriptions. Overall these models seem to predict the following consistently negative pattern:

Contrast of the Ascriber Salience for the Ascriber Stakes for the Subject

\begin{tabular}{lll}
\hline No No No & No \\
\hline
\end{tabular}

These models seem to be off to a slightly better start than the subject sensitive models (§6.1), in that at least their predictions agree with the data in the rightmost column. This is a step forward.

But the invariantist aspect of these models is still precluding them from predicting a contrast or salience effect. So we take the leftmost two columns of data to present a prima facie challenge to the plausibility of any invariantist models of knowledge ascriptions, be they subject sensitive or classical.

Overall it seems to us that the best hope for the invariantist who wants a descriptively adequate account of knowledge ascriptions is to adopt a classical model. This at least spares her from having to explain away the lack of observed stakes effects. She might then invoke some combination of conversational pragmatics and/or performance errors to try to mimic the predictions of the contrastive model with respect to contrast effects and salience effects. Such a strategy would promise to preserve an invariantist 
semantics, while still yielding the right predictions about what people will say. We will now consider how this strategy might be implemented.

\subsection{Conversational Pragmatics and Performance Errors}

There are many ways in which the (subject sensitive or classical) invariantist might invoke conversational pragmatics and/or performance errors to try to mimic the predictions of the contrastive model. We will focus on the two ways which we think hold the most promise, and raise concerns for each.

First, the invariantist might invoke Grice's (1989) maxims of Relevance and Quality. The maxim of Relevance enjoins cooperative conversationalists to "Be relevant" (1989: 27) by providing information pertaining to the conversation at hand. If one thinks of the conversation at hand as oriented towards the question under discussion, then Relevance can be glossed as: speak to the question (Roberts 2004: 216). Given that the contrasts operative in simple knowledge-that ascriptions can be traced to the contrasts provided by the question under discussion, Grice's maxim of Relevance can then be understood as providing a way for the contextually salient contrasts to be involved in pragmatic implicatures.

Grice's maxim of Quality covers the injunction: "Do not say that for which you lack adequate evidence" (1989: 27). If one then thinks of the adequate evidence requirement as involving something like the elimination of relevant alternatives, then the invariantist can combine Relevance and Quality to replicate the predictions of the contrastive model, on which knowledge ascriptions require the elimination of the relevant alternatives. This is what is promising about this first strategy. ${ }^{25}$

Here is how this first strategy might be applied to our study on context sensitivity (§4.3). In that study we looked at knowledge ascriptions of the form "Mary now knows that Peter stole the rubies," produced in (i) a context in which the question under discussion was "Who stole the rubies?", versus (ii) a context in which the question under discussion was "What did Peter steal?" The first move of this strategy is to say that the knowledge ascription involved is true, regardless of context (after all, an invariantist strategy cannot allow context to affect truth-value). What then needs explaining is why ordinary speakers tend to disagree with this alleged truth when produced in context (ii), where the question under discussion was "What did Peter steal?" The second move is to maintain that this question pragmatically makes relevant contrasts in which Peter stole something else, and so pragmatically requires the asserter to have evidence which eliminates these contrasts. So asserting "Mary now knows that Peter stole the rubies" when this question is under discussion generates the false implicature that Mary can eliminate alternatives in which Peter stole something else. No wonder-concludes the invariantist who takes this first strategy—ordinary speakers will disagree with this true claim. 
We think this is an interesting and plausible strategy, especially in light of the fact that it relies on antecedently plausible pragmatic mechanisms. But still we have doubts as to whether this strategy will allow the invariantist to fully explain the data. Our main concern is that this strategy does not go far enough. Recall that the data is that ordinary speakers will tend to disagree with the knowledge ascription. Where Relevance and Quality combine to yield false implicatures, we think that ordinary speakers will tend to avoid asserting the claim with these false implicatures. But we are not convinced that ordinary speakers will go so far as to disagree with the claim. (Note that we are not saying that false implicatures can never lead people to disagree with true claims. We are only saying that false implicatures which combine Relevance and Quality in this way do not trigger disagreement. ${ }^{26}$ )

To illustrate what happens when Relevance and Quality combine in this way, imagine that Ann and Ben are discussing where their friend Carl might be right now. Carl in fact is visiting Mexico, but neither Ann nor Ben have any real evidence on the matter. Suppose that Ben then says "Carl is in Mexico." Given Relevance and Quality, Ben's assertion falsely implicates that he can eliminate alternatives in which Carl is not in Mexico. This is parallel to the invariantist idea under discussion. But now ask yourself the following question: do you disagree with Ben's claim that Carl is in Mexico? We think few people will go so far as to disagree with Ben's claim, despite the fact that it generates the false implicature that Ben can eliminate relevant alternatives in which Carl is not in Mexico. We expect people to harbor various doubts about Ben, but not to disagree with his claim. If this is right then the first invariantist strategy - interesting and plausible though it may be - falls short of explaining the data.

Indeed there are other well known problems arising for the invariantist who would appeal to Grice to try to explain the data under discussion, including the problem of cancelability. Mere implicatures are generally cancelable without contradiction. For instance, when the teacher reports "Some of the students passed" this generates the scalar implicature that not all of the students passed. But such an implicature can be canceled. The teacher can follow up with the claim "Indeed, all of the students passed." She does not thereby contradict herself. The alleged implicatures the invariantist is invoking, however, do not seem cancelable without contradiction. Thus consider: "Mary now knows that Peter stole the rubies, but I don't mean to suggest that Mary can rule out the prospect that Peter stole something else." We find it hard to hear this as a coherent thought. Indeed the most natural reading of this claim would treat the second conjunct (after "but...") as retracting something claimed in the first conjunct. As the cancelability problem does not directly concern the interpretation of our data, we will not discuss it further here. But suffice it to say that there is independent reason to doubt that a Gricean move is the right sort of move to make on this point. 
As a second invariantist strategy - this time based on performance errors rather than conversational pragmatics - the invariantist might invoke the phenomenon of shallow processing (Sanford and Sturt 2002; Sanford et al 2006). It seems that linguistic input that is not in focus is sometimes only partially processed. For instance, Erickson and Mattson (1981) asked people: "How many animals of each type did Moses put on the ark?" The typical answer they got was two. Few people seemed to notice that the question asks about Moses, who was presumably not involved with boarding any animals onto arks. If one thinks of the contrasts as controlling the locus of focus, then the invariantist might say that certain knowledge ascriptions, though false, are accepted because their false aspect goes unprocessed. ${ }^{27}$

Here is how this second strategy might be applied to our study on context sensitivity ( $\$ 4.3)$. The first move of this strategy is to say that "Mary now knows that Peter stole the rubies" is invariantly false, regardless of whether the question under discussion is "Who stole the rubies?" or "What did Peter steal?" (This is the opposite of the view involved in the first strategy, on which "Mary now knows that Peter stole the rubies" was said to be invariantly true). Indeed the pursuer of this second strategy might buttress her case by noting that people can presumably be made to retract their knowledge claims on the basis of closure considerations. The idea-which we borrow from an anonymous referee-is that if someone has agreed to the claim that Mary now knows that Peter stole the rubies, one might then ask this person whether Mary can only know that Peter stole the rubies if she knows what Peter stole. This person might then retract her original knowledge claim in response, which would buttress the idea that the original knowledge claim was made in error. ${ }^{28}$

What now needs explaining is why ordinary speakers tend to agree with this alleged falsity, when it is produced in a context oriented towards the question "What did Peter steal?" The second move of this strategy is to invoke shallow processing, in order to maintain that this question pulls people's attention towards the "Peter" part and away from the "rubies" part, so that people effectively read "Mary now knows that Peter stole the rubies" as "Mary now knows that Peter blah blah blah". In other words, people pay no more attention to "rubies" in our probe than they do to "Moses" in the Erickson and Mattson probe. No wonder-concludes the invariantist who takes this second strategy — ordinary speakers will agree with this false claim. They don't notice or consider that Mary has no evidence relevant to the "rubies" part.

We would certainly acknowledge the existence of shallow processing effects. We just think that there are both shallow processing and contrast effects, and suspect that it would be a mistake to try to reduce either effect to the other. Our reason for thinking that the contrast effect is a separate effect is that some of our studies seem to involve no shift in which part of a given sentence gets processed (or how deeply it gets processed). 
Thus consider our study on salience sensitivity ( $(5)$. By raising the prospect that the bank might change its hours in a concrete and vivid way, we were able to shift whether people were willing to agree with the claim that Hannah knows that the bank will be open on Saturday. But - unlike in the context sensitivity study — we did not generate this shift by pulling people's attention away from one part of the sentence towards a different part of the sentence. Indeed, to use a shallow processing explanation of our study on salience sensitivity, one would have to first maintain the quasi-skeptical view that in fact Hannah does not know that the bank will be open on Saturday. We suspect that most invariantists will already reject the strategy at this point. One would then have to maintain that ordinary speakers do not fully process either "the bank," "will be open," or "on Saturday," until Sarah mentions the anecdote in which a bank changed its hours. We see little motivation for this claim. All in all then we regard the second invariantist strategy-though based on an effect which we would not deny-as not fully explaining the data.

Of course there may be further invariantist strategies for using conversational pragmatics and/or performance errors to explain the contrast effect. We have only addressed the two strategies we consider most promising. We would like to invite the invariantist to provide a better proposal if she can..$^{29,30}$

\subsection{Other Contextualist Models}

It remains to consider other contextualist models for knowledge ascriptions. By 'other contextualist models' we mean models which are contextualist (allowing that one ascriber could truly say " $s$ knows that $p$," while a second ascriber in a second context could truly deny " $s$ knows that $p$ ", for fixed $s$ and $p$, at a single world and time), but which do not trace the context sensitivity to shifts in relevant alternatives. For instance, Cohen $(1988,1999)$ offers a model in which context sensitivity concerns the degree of evidence regarded as sufficient for justification, and DeRose (1995) offers a model in which context sensitivity arises from the distance in logical space through which the subject is required to track truth.

Such alternative contextualist models seem to issue the following predictions:

Contrast of the Ascriber Salience for the Ascriber Stakes for the Subject

\begin{tabular}{lll}
\hline No Yes & No \\
\hline
\end{tabular}

These models are two steps forward from subject sensitive invariantist models (§6.1), and one step forward from subject insensitive invariantist models (§6.2). But they remain one step back from the contrastive model (§3.2), 
in that they still fail to predict a contrast effect. After all, these alternatives models - by stipulation - are those models that do not take knowledge ascriptions to be sensitive to the contrast.

Indeed, these alternative contextualist models seem to be ill suited to predict the observed intuitive sensitivity to the contents of 'rather than' phrases and embedded questions. Starting with Cohen's model, there seems to be no obvious mechanism that would link the contents of 'rather than' phrases or of embedded question with the degree of evidence regarded as sufficient for justification. Why for instance should "Mary now knows that Peter rather than anyone else stole the rubies" call for a lower threshold of evidence than "Mary now knows that Peter stole the rubies rather than anything else"? We don't mean to suggest that no mechanism can possibly be provided. We only mean to suggest that Cohen's model does not provide any such mechanism as formulated, and that we see no obvious suggestion for such how a mechanism might work.

Turning to DeRose's model, there likewise seems no obvious mechanism that would link the contents of 'rather than' phrases or of embedded questions with the distance in logical space through which the subject must track truth. Why for instance should "Mary now knows that Peter rather than anyone else stole the rubies" require Mary to track the truth through a smaller range of worlds than does "Mary now knows that Peter stole the rubies rather than anything else"? Again we don't mean to suggest that no mechanism can possibly be provided, but only to suggest that DeRose's model provides no such mechanism, and that we see no obvious supplementation. ${ }^{31}$

Indeed, we think that the contrast effect is a more subtle, local effect than Cohen's or DeRose's model can predict (c.f. Schaffer 2005b). For both of these models are global, in the following sense. Suppose - to work with Cohen's model - that $s$ has the same degree of evidence $d$ for two propositions $p 1$ and $p 2$. Then no context will be able to pull them apart. For instance, suppose that Kate has degree of evidence .95 for both the claim that it is 11:45am and the claim that she is on Main Street. Then on Cohen's model no context — even one that raises all sorts of doubts about the workings of Kate's watch but which raises no doubts whatsoever about the accuracy of local street signs - can mark any distinction. Likewise - to work with DeRose's model now-suppose that $s$ can track the truth of $p 1$ to the same distance in logical space as she track the truth of $p 2$. Then on DeRose's model no context can distinguish $s$ 's epistemic status with respect to $p 1$ and $p 2$.

Yet the kind of contrasts that impact our knowledge ascriptions seem more local. It seems possible to raise salient error possibilities with respect to one proposition (e.g. that it is 11:45am) that do not count as error possibilities with respect to another proposition (e.g. that the street is Main Street). For instance, one might consider whether the subject knows that it is 11:45am, in light of the prospect that her watch might have broken in the last hour. 
Obviously the proponent of an alternative contextualist model could try to invoke conversational pragmatics and/or performance errors to try to explain the contrast effect, with its more subtle local features. At present we see no new way for her to go beyond those attempts we have already considered for the invariantists (§6.3). Though again we invite further proposals.

\section{Conclusions}

The existing debate over contextualism is based in large part on claims about what ordinary speakers will say about bank cases $(\S 1)$. But these claims do not survive empirical scrutiny. Ordinary speakers do not say what philosophers say they will say (§2).

The empirical data about what ordinary speakers will say suggests that our intuitions are in fact sensitive to contrasts and salient error possibilities, but insensitive to stakes ( $\$ \S 4-5)$. We have developed a contrastive model of knowledge ascriptions which predicts and explains this data (§3). We have then argued that rival invariantist and contextualist models have trouble explaining this data ( $(6)$. And so, pending further proposals, we conclude that the contrastive model provides the best explanation for our intuitions about knowledge. ${ }^{32}$

\section{Notes}

${ }^{1}$ Indeed, the only epistemologist we are aware of who has voiced any challenge to these intuitions is Stone (2007). Though the challenges Stone raises are very different from those we will review in $\S 2$.

${ }^{2}$ The same two confounds recur in Cohen's airport cases (1999: 58), Fantl and McGrath's train cases (2002: 67-8), and Stanley's variants of the bank cases (2005: 3-4).

${ }^{3}$ Neta and Phelan assume, as a point of contact between evidence and ordinary terms of epistemic appraisal, that the better one's evidence is for $p$, the more confident in $p$ one ought to be.

${ }^{4}$ To ensure the generality of their conclusion, Neta and Phelan conducted three separate studies using three different vignettes. In each study, participants were randomly assigned to receive either a low stakes case or a high stakes case. Subjects then rated the degree to which the character in the case should be confident on a scale from 1 ('not confident') to 7 ('very confident'). Collapsing across the three studies, they found a mean of 5.25 for the low stakes cases and 5.2 for the high stakes cases. This difference is not even close to statistically significant $(\mathrm{p}>.8)$.

${ }^{5}$ Feltz and Zarpentine did find statistically significant differences between (i) their low stakes case, and a case with a low stakes attributor considering whether a high stakes subject knows, as well as between (ii) a high stakes case in which the subject is unaware of the stakes, and a case with a low stakes attributor considering whether a high stakes subject knows. But they explain this away by noting (with empirical support) that people are generally more willing to agree with first-personal knowledge ascriptions than with third-personal knowledge ascriptions.

${ }^{6}$ Participants rated the sentence on a scale from 1 ('disagree') to 5 ('agree'). The mean ratings for the three conditions were: baseline 3.83; high stakes 3.71; salient error possibilities 3.64. All three of these means were significantly higher than the midpoint. Moreover, pairwise comparisons among the three conditions showed no significant effects. 
${ }^{7}$ Beebe and Jensen (manuscript) have conducted an impressive array of further studies showing that this same pattern of responses arises in other cases with the same structure.

${ }^{8}$ Experimental philosophy has of course been subject to continuing controversy (Kauppinen 2007; Knobe and Nichols 2008; Ludwig 2007; Sosa 2006), and critics have pointed to a number of ways in which it might be problematic to infer too directly from facts about people's responses in experimental studies to the nature of the corresponding concepts. One of the most important points here is that people might ordinarily be making certain sorts of errors which, in the light of more systematic reflection, philosophers would be able to correct (e.g., Kauppinen 2007; Ludwig 2007). We agree that this is a very serious worry. However, instead of trying to address this worry in the abstract, we think it will prove more fruitful to focus on the specific experimental studies we will be relying on here and to consider particular hypotheses about how the responses elicited in our particular experiments might be infected with error. We take up this task below in $\S 6.3$ (see especially note 30 ).

${ }^{9}$ A novel prediction of our contrastive explanation of moral valence effects - pointed out to us by John Turri-is that moral valence effects should diminish to the extent that one can successfully hold fixed the contrast by independent means. Given that we use things like 'rather than' phrases as a way to to fix contrasts $(\S 4.1)$, this means that we predict that the moral valence effect should diminish if we move to constructions like "Did the chairman know that the new program would help (/hurt) rather than hurt (/help) the environment?" We do not yet know if this prediction will be borne out.

${ }^{10}$ One commonly suggested alternative explanation is that people ascribe knowledge to the chairman as part of an attempt to blame him for his actions. ('He specifically knew that this would happen!') To rule out this alternative, we conducted a simple follow-up to Beebe and Buckwalter's study. Our follow-up added an additional character, an environmentalist who knew that scientists were predicting helpful or harmful effects and then learned about the chairman's decision to go ahead with the program. The question then was whether participants would agree that the environmentalist knew that the environment would be helped or harmed. In this new version, there is no question of blaming the environmentalist for the outcome, but all of the factors we appealed to in our contrastivist explanation remain unchanged. The familiar asymmetry remained. On a scale from 1 ('disagree') to 7 ('agree'), we found a rating of 4.8 in the harm case, and 2.8 in the help case, yielding a statistically significant difference, $t(26)=3.3$, $p<.01$.

${ }^{11}$ We are neutral as to whether contrastivity is a special feature of certain specific concepts (including knowledge), or whether contrastivity is a more general feature of cognition. Either way, our concept of knowledge will be contrastive. Whether this is a specific feature of knowledge or a more general feature of cognition is an empirical question. One way to test this would be to try analogues of our experiments below on various concepts other than that of knowledge.

12 Versions of contrastivism have since been defended by Johnsen (2001), Morton and Karjalainen (2003), Sinnott-Armstrong (2004), Blaauw (2004), and Schaffer (2004, 2005a), inter alia.

13 Though contrastivism, unlike standard contextualism, upholds an invariantist semantics for "knows," always taking it to denote one and the same three place relation. According to contrastivism, what varies with context is not the meaning of "knows" but rather the value of its third argument when left implicit. Since this sense in which contrastivism differs from contextualism will not prove relevant to the interpretation of our data, we will group contrastivism in with contextualism for present purposes.

${ }^{14}$ Or at least, the contrastive model does not directly predict any stakes effect on its own. The contrastive model could be used to predict a stakes effect, if coupled with the further speculative claim that high stakes tends to trigger consideration of a wider range of scenarios (Schaffer 2006). But given the empirical evidence to date we see no need to pursue this speculation further. 
${ }^{15}$ Indeed, just as contextualists have relied on claims about 'our intuitions' ( $\$ 1$ ), so contrastivists have relied on similar claims: "Knowledge ascriptions are contrast-sensitive. That is, our intuitions about whether knowledge obtains depend not only on the subject $s$ and the proposition $p$, but also on which contrast proposition $q$ is in question" (Schaffer 2008: 235). Schaffer goes on to speak of "the contrastive data" (2008: 237), but provides merely anecdotal support for his claims, from his intuitions and those of his informants.

${ }^{16} N=100$ people spending time in the Canberra Centre Mall in Canberra, Australia, $t$ $(98)=3.4, p=.001$.

In each of the experiments reported here, we also included a 'distracter question' to disguise the true purpose of the experiment. (For example in this first study, the distracter question asked participants whether they agreed or disagreed with the sentence: 'Mary will eventually succeed in catching the thief.') The results for these distracter questions will not be reported here.

${ }^{17}$ We thank an anonymous referee for helping us recognize this point.

${ }^{18}$ For further discussion of the semantics of knowledge-wh constructions, see Schaffer 2007.

${ }^{19} N=200$ people spending time in the Canberra Centre Mall in Canberra, Australia, $\mathrm{t}(198)=7.2, p<.001$.

${ }^{20}$ As a more specific hypothesis, there are reasons for thinking that every context comes with a question under discussion (Carlson 1983, Ginzburg 1996, Roberts 2004). The question under discussion may then provide a source of contextually salient contrasts.

${ }^{21} N=200$ people spending time in the Canberra Centre Mall in Canberra, Australia, $t(198)=11.0, p<.001$.

${ }^{22} N=200$ people spending time in the Canberra Centre Mall in Canberra, Australia, $t(198)=11.3, p<.001$.

${ }^{23}$ Such theories have been defended by Fantl and McGrath 2002, Hawthorne 2004, and Stanley 2005. Hawthorne calls his approach "sensitive moderate invariantism," and Stanley labels his approach "interest relative invariantism."

${ }^{24}$ For instance, Fantl and McGrath 2002 defend a subject sensitive model as reconciling a fallibilist conception of knowledge with some plausible principles about the role of knowledge in practical reasoning. See also Hawthorne and Stanley 2008.

${ }^{25}$ Rysiew 2001 and Brown 2006 suggest related Gricean pragmatic explanations for the pull of skeptical arguments.

${ }^{26}$ We thank an anonymous referee for pressing us to clarify this point.

${ }^{27}$ We thank Jennifer Nagel for bringing this line of explanation to our attention, and for further discussion of these issues. A related proposal, suggested to us independently by Joshua May and Ernest Sosa, has it that the different contrasts trigger different de re readings of the knowledge ascriptions. On the de re view, "Mary now knows that Peter rather than anyone else stole the rubies" has a prominent reading on which it says, in effect: "Of the rubies, Mary now knows that Peter stole them." While "Mary now knows that Peter stole the rubies rather than anything else" has a different prominent reading on which it says, in effect: "Of Peter, Mary now knows that he stole the rubies." The idea here is that the material that is not in the locus of focus is material that moves outside the scope of "knows," so that the subject (Mary) need not conceive of it under the description provided. In particular, "of the rubies, Mary now knows that Peter stole them" does not require Mary to conceive of the rubies as "the rubies." She might merely conceive of the rubies as "the things that were taken from the safe." Our objection to the performance error explanation will apply equally to the de re reading explanation, so we will not consider the de re reading explanation specifically in the main text.

${ }^{28}$ Assuming that people in fact will retract their knowledge ascriptions on the basis of such closure considerations (an empirical claim), there are at least two possible interpretations of such retraction. One interpretation (the one mentioned in the main text) is that the retraction is correct and the original retracted claim was false. But a second interpretation is that the original retracted claim was true and the retraction is incorrect. Indeed one of the lessons of skeptical arguments is that closure considerations seem able to make people retract virtually any 
knowledge claim. So it seems that everyone but the skeptic needs to allow for cases in which we incorrectly retract a true knowledge claim. Perhaps we incorrectly retract due to conversational pragmatics or as a result of performance errors (such as the contextualist idea of semantic blindness). What is needed is an explanation of why one might retract in the face of skeptical arguments. Then one needs to see whether or not such an explanation would cover the retraction case mentioned in the main text. We think that this is an important issue but one which would be premature to discuss further here, pending data as to whether the retraction really takes place, and tests that might discriminate between different explanations for retraction.

${ }^{29}$ See Nagel (2010) for a further invariantist strategy.

${ }^{30}$ As mentioned in note 8 , one of the most serious criticisms of experimental philosophy is the criticism that one cannot read conceptual structure off of survey results, since survey results are influenced by conversational pragmatics and distorted by performance errors. By considering the two main hypotheses about how our specific results might have been impacted by pragmatic and performance based factors, we hope that we have addressed this objection as it applies to our specific studies.

${ }^{31}$ The primary mechanism that DeRose does provide for context sensitivity is his Rule of Sensitivity (1995: 35-9), according to which the subject is required to track the truth of $\mathrm{p}$ at least out to the nearest word $\sim p$ world. But in the contrast effect cases what seems crucial is that the subject be epistemically equipped to handle the relevant alternatives, regardless of whether or not these count as the nearest $\sim$ p-worlds. For instance, for Mary to know whether Peter stole the rubies rather than anything else, intuitively Mary needs to be epistemically equipped to handle the relevant alternatives in which Peter stole something else-regardless of how big a departure from actuality it might take to replace the rubies with anything else.

${ }^{32}$ Special thanks to Jennifer Nagel for repeated discussions and detailed comments. For helpful comments and suggestions, we are grateful to James Beebe, Jessica Brown, Wesley Buckwalter, Dave Chalmers, Tamar Gendler, Mikkel Gerken, Joshua May, Ram Neta, Ángel Pinillos, Eric Schwitzgebel, Walter Sinnott-Armstrong, Ernie Sosa, John Turri, Jonathan Weinberg, and Aaron Zimmerman. Isobel Nye helped us conduct some of the surveys. We also received very useful feedback from two blog discussions at Certain Doubts, and from audiences at Yale University, the University of Buffalo, the Arché Epistemic Contextualism Workshop, the 2010 AAP in Melbourne, and the Corridor Reading Group.

\section{References}

Austin, J. L. 1946. "Other Minds," Proceedings of the Aristotelian Society 20: 149-87.

Bach, Kent 2010. "Knowledge In and Out of Context," Knowledge and Skepticism, eds, Joseph Keim Campbell, Michael O'Rourke, and Harry S. Silverstein 105-36, MIT Press.

Beebe, James and Wesley Buckwalter 2010. "The Epistemic Side-Effect Effect," Mind \& Language 25: 474-98.

Beebe, James and Mark Jensen manuscript. "Surprising Connections Between Knowledge and Intentional Action: The Robustness of the Epistemic Side-Effect Effect."

Blaauw, Martijn 2004. Contrastivism: Reconciling Skeptical Doubt with Ordinary Knowledge. Dissertation in Philosophy, Free University of Amsterdam.

Brown, Jessica 2005. "Comparing Contextualism and Invariantism on the Correctness of the Contextualist Intuitions," Grazer Philosophische Studien 69: 71-100.

2006. "Contextualism and Warranted Assertibility Manoeuvers," Philosophical Studies 130: 407-35.

Buckwalter, Wesley 2010. "Knowledge Isn’t Closed on Saturdays," Review of Philosophy and Psychology 1: 395-406.

Carlson, Lauri 1983. Dialogue Games: An Approach to Discourse Analysis. Reidel.

Chisholm, Roderick 1977. Theory of Knowledge, $2^{\text {nd }}$ edition. Prentice Hall.

Cohen, Stewart 1988. "How to be a Fallibilist," Philosophical Perspectives 2: 91-123. 
1999. "Contextualism, Skepticism, and the Structure of Reasons," Philosophical Perspectives 13: 57-89.

Cushman, Fiery, Joshua Knobe, and Walter Sinnott-Armstrong 2008. "Moral Judgments Impact Doing/Allowing Judgments," Cognition 108: 281-9.

DeRose, Keith 1992. "Contextualism and Knowledge Attributions," Philosophy and Phenomenological Research 52: 913-29.

1995. "Solving the Skeptical Problem," Philosophical Review 104: 1-52.

1999. "Contextualism: An Explanation and Defense," The Blackwell Guide to Epistemology, eds. John Greco and Ernest Sosa: 182-205. Basil Blackwell.

2005. "The Ordinary Language Basis for Contextualism and the New Invariantism," Philosophical Quarterly 55: 172-98.

Dretske, Fred 1970. "Epistemic Operators," The Journal of Philosophy 67: 1007-23.

Erickson, Thomas and Mark Mattson 1981. "From Words to Meanings: A Semantic Illusion," Journal of Verbal Learning and Verbal Behavior 20: 540-52.

Fantl, Jeremy and Matthew McGrath 2002. "Evidence, Pragmatics, and Justification," The Philosophical Review 111: 67-94.

Feltz, Adam and Chris Zarpentine forthcoming. "Do You Know More When it Matters Less?" Philosophical Psychology.

Ginzburg, Jonathan 1996. "The Semantics of Interrogatives," The Handbook of Contemporary Semantic Theory, ed. Shalom Lappin: 385-422. Basil Blackwell.

Grice, H. P. 1989. "Logic and Conversation," Studies in the Way of Words: 1-144. Harvard University Press.

Hawthorne, John 2004. Knowledge and Lotteries. Oxford University Press.

Hawthorne, John and Jason Stanley 2008. "Knowledge and Action," Journal of Philosophy 105: 571-90.

Johnsen, Bredo 2001. "Contextualist Swords, Skeptical Plowshares," Philosophy and Phenomenological Research 62: 385-406.

Kauppinen, Antti 2007. "The Rise and Fall of Experimental Philosophy," Philosophical Explorations 10: 95-118.

Knobe, Joshua 2003. "Intentional Action and Side Effects in Ordinary Language," Analysis 63: 190-3.

Knobe, Joshua and Shaun Nichols 2008. "An Experimental Philosophy Manifesto," Experimental Philosophy, eds. Joshua Knobe and Shaun Nichols: 3-14. Oxford University Press.

Ludwig, Kirk 2007. "The Epistemology of Thought Experiments: First vs. Third Person Approaches," Midwest Studies in Philosophy 31: 128-59.

McCloy, Rachel and Ruth Byrne 2000. "Counterfactual Thinking about Controllable Events," Memory \& Cognition 28: 1071-8.

May, Joshua, Walter Sinnott-Armstrong, Jay G. Hull, and Aaron Zimmerman 2010. "Practical Interests, Relevant Alternatives, and Knowledge Attributions: An Empirical Study," Review of Philosophy and Psychology 1: 265-73.

Moore, G. E. 1959. "A Defence of Common Sense,” Philosophical Papers: 32-59. George, Allen and Unwin.

Morton, Adam and Antti Karjalainen 2003. "Contrastive Knowledge," Philosophical Explorations 6: 74-89.

Nadelhoffer, Thomas and Eddy Nahmias 2007. "The Past and Future of Experimental Philosophy," Philosophical Explorations 10: 123-49.

N'gbala, Ahooni and Branscombe Nyla 1995. "Mental simulation and causal attribution: When simulating an event does not affect fault assignment," Journal of Experimental Social Psychology 31: 139-62.

Nagel, Jennifer 2008. "Knowledge Ascriptions and the Psychological Consequences of Changing Stakes," Australasian Journal of Philosophy 86: 279-94. 
2010. "Knowledge Ascriptions and the Psychological Consequences of Thinking About Error," Philosophical Quarterly 60: 286-306.

Neta, Ram and Mark Phelan manuscript. "Evidence that Stakes Don't Matter for Evidence." Oppenheimer, Daniel 2004. "Spontaneous Discounting of Availability in Frequency Judgment Tasks," Psychological Science 15: 100-5.

Pettit, Dean and Joshua Knobe 2009. "The Pervasive Impact of Moral Judgment," Mind \& Language 24: 586-604.

Roberts, Craige 2004. "Context in Dynamic Interpretation," The Handbook of Pragmatics, eds. Laurence R. Horn and Gregory Ward: 197-220. Basil Blackwell.

Rysiew, Patrick 2001. "The Context-Sensitivity of Knowledge Attributions," Noûs 35: 477-514.

Sanford, Alison, Anthony Sanford, Jo Molle, and Catherine Emmott 2006. "Shallow Processing and Attention Capture in Written and Spoken Discourse," Discourse Processes 42: 10930 .

Sanford, Anthony and Patrick Sturt 2002. "Depth of Processing in Language Comprehension: Not Noticing the Evidence," Trends in Cognitive Sciences 6: 382-6.

Schaffer, Jonathan 2004. "From Contextualism to Contrastivism," Philosophical Studies 119: 73-103.

2005a. "Contrastive Knowledge," Oxford Studies in Epistemology 1: 235-71.

2005b. "What Shifts? Thresholds, Standards, or Alternatives?" Contextualism in Philosophy, eds. Gerhard Preyer and Georg Peter: 115-30. Oxford University Press.

2006. "The Irrelevance of the Subject: Against Subject-Sensitive Invariantism," Philosophical Studies 127: 87-107.

2007. "Knowing the Answer," Philosophy and Phenomenological Research 75: 383-403.

2008. "The Contrast-Sensitivity of Knowledge Ascriptions," Social Epistemology 22: 235-45.

Sherman, Stephen, Robert Cialdini, Donna Schwartzmann, and Kim Reynolds 1985. "Imagining can Heighten Or Lower the Perceived Likelihood of Contracting a Disease," Personality and Social Psychology Bulletin 11: 118-27.

Sinnott-Armstrong, Walter 2004. Pyrrhonian Skepticism. Oxford University Press.

Sosa, Ernest 2006. "Experimental Philosophy and Philosophical Intuition," Philosophical Studies 132: 99-107.

Stanley, Jason 2005. Knowledge and Practical Interests. Oxford University Press.

Stone, Jim 2007. "Contextualism and Warranted Assertion," Pacific Philosophical Quarterly 88: 92-113.

Ulatowski, Joseph 2008. "How Many Theories of Act Individuation are There?" Dissertation in Philosophy, University of Utah. 